\title{
Filosofía de la cooperación
}

\author{
Javier Divar Garteiz-Aurrecoa \\ Catedrático de la Universidad de Deusto \\ Presidente de la AIDC
}

Sumario: I. Los estatalistas. II. Los pioneros del cooperativismo. III. La reglamentación cooperativa. IV. La Empresa Cooperativa. V. Tendencias Cooperativas. VI. Bibliografía.

Resumen: La evolución del cooperativismo como doctrina social y económica parte de los asociacionistas y de los mutualistas históricos, asentándose en los llamados pioneros sociales, ideario que se tecnifica con el movimiento rochdaliano, que caracteriza estatutaria y legalmente el cooperativismo, para culminar en la empresarialización desarrollada por el cooperativismo alemán.

Palabras clave: Cooperativismo. Pensamiento. Evolución.

Abstract: The evolution of cooperativism as a social and economic doctrine is based on ideas put forth by historical advocates of associations and mutual aid. It consolidated with the so called social pioneers. This ideology was updated with the Rochdale movement which provided cooperatives with by-laws and a legal system and led to the corporatization developed by German cooperatives.

Keywords: Cooperativism. Thought. Evolution. 
El pensamiento social, entendido como sustento para un sistema de organización de la comunidad, de la vida en sociedad, en forma que la meta colectiva sea el bien y el sustento del común de los partícipes, se ha expresado en el común de las civilizaciones. Aunque la formulación científica primera de las ideas socializadoras se encuentra en la filosofía helénica, sobre todo en el pensamiento de Platón.

Pero, como queda dicho, en todas las culturas y pueblos encontramos formas de cooperación entre los seres humanos, sin previas formulaciones jurídicas ni asentamientos normativos. Es decir, son espontáneos movimientos de mutualidad, aprovechamiento común, solidaridad y recíproca ayuda.

No existen científicos «inventores» del cooperativismo, es sencillamente (y esa es su mayor grandeza) una formulación del ser humano (el «buen salvaje») no envilecido por la deshumanizada relación competitiva de una sociedad económicamente insolidaria.

Es por ello que Carlos Gide, el primer maestro de la Economía Cooperativa, decía que el cooperativismo es un movimiento radicalmente popular, directamente nacido del pueblo y para su beneficio.

Por ese origen natural y popular, todos los pueblos han tenido comportamientos económicos cooperativos, puesto que está probado que los humanos reaccionan con similares comportamientos ante circunstancias semejantes.

En ese sentido amplísimo podemos decir sin miedo a errar que las ideas y movimientos socializadores han sido universales y bajo variadas formas de cooperación. Por todo ello que en un sentido no científico la socialización es un fenómeno universal y sostenido históricamente.

Pero una ideología socialista expresa, clara y directa, no se produce sino hasta el triunfo del advenimiento mercantilista en los tiempos finales de la Edad Moderna, como reacción frontal contra la naciente explotación capitalista, sutil en sus formas pero de consecuencias mucho más profundas que la brutal explotación feudal (que ya había tenido también sus resistencias campesinas, en general desorganizadas y más emotivas que prácticas).

En los siglos XVII y XVIII, muy especialmente en este último, encontramos a los autores pioneros del cientifismo socialista y por cierto que con precisas elaboraciones técnicas muy anteriores a Marx (1818-1883) y Engels (1820-1895), aunque se considere el marxismo como el origen del llamado «socialismo científico».

Ciertamente existe otro socialismo anterior, humanista y filosófico. Como ya dijo el Prof. G.D.H. Cole, en su «Historia del Pensamiento Socialista», no existe un concepto unívoco del socialismo. 
Esas teorías socialistas primeras han dado en llamarse «de los utópicos» como contraposición a las de los «científicos». El Ilamado «socialismo utópico» entra de lleno en la tradición «socializadora» popular, platoniana y religiosa. Tiene como inmediatas precursoras a las denominadas «novelas sociales», destacadamente la «Utopía» de Tomás Moro (1478-1536) y «La Nueva Atlántida» de Bacón (1561-1626), expresiones varias del deseo intelectual de un mundo mejor, de una vida nueva asentada sobre la solidaridad entre los seres humanos y la justicia social.

Los primeros idearios cooperativistas fueron mantenidos por los llamados asociacionistas, entre los que destacan P.C. Plockboy y J. Bellers, que en el siglo XVII redactaron sus programas basados en los fundamentos de la moral cristiana, en la idea liberadora asentada en la igualdad de origen y en el destino común de todos los seres humanos. Se trata de conseguir el reino de Dios en la Tierra, la hermandad de todos los humanos como hijos de Dios.

Peter Cornelius Plockboy, nacido en Holanda en 1620, se había instalado en Inglaterra. Como sincero creyente encuadraba su vida en los postulados religiosos del cristianismo, por lo que tomó contacto con el reformismo protestante de las «Asociaciones» de George Fox, considerado el fundador del movimiento cuáquero.

George Fox había nacido en 1624 en el Condado de Leicester, en el seno de una familia humilde que le proporcionó una esmerada educación religiosa. Su personal interpretación de la Biblia le llevó a disidir de la línea oficial de la Iglesia en Inglaterra, al punto que fue denunciado por defender sus posiciones «naturalistas» de los Textos Sagrados, bajo la acusación de blasfemia, por lo que fue encarcelado en 1650 (sucesivamente sufrió persecución y penas de cárcel por sus creencias religiosas, que mantuvo siempre con valor y consecuencia).

George Fox y sus seguidores, entre ellos Peter C. Plockboy, volvieron a los orígenes de los primeros cristianos en su ideal de vida comunitaria y de ayuda mutua, formando "Sociedades de Amigos», base de la organización cuáquera, trabajando en comunidad, apoyándose entre sí y leyendo y comentando entre «los amigos» o hermanos la Biblia, sin sacerdotes ni sacramentos, bajo su propio criterio.

Comparativamente Plockboy, observando las miserias de las familias campesinas y del proletariado urbano, dedujo que la sociedad en su conjunto se basaba en la insolidaridad y el desamor hacia el prójimo, en grave incumplimiento de los principios evangélicos.

Como los ricos habían acomodado las instituciones a sus beneficios personales, con explotación inmisericorde de los humildes, comprendió que sólo la unión entre éstos era camino para superar las adversidades 
populares, mediante una vida de asociación cooperativa integral, a semejanza de las comunidades cuáqueras.

En 1659 publicó un folleto en el que expresaba su propuesta asociacionista de familias integradas en grupos económicos comunitarios. Se trataba de organizar colonias integradas por varias familias que coadyuvasen unos con otros en la solución colectiva del problema de la habitación, del trabajo asociado entre los colonos y del consumo común.

Ese folleto, publicado por Plockboy bajo el título de «Ensayo sobre un proceso que les haga felices a los pobres de esta nación y a los de otros pueblos, consistiendo en reunir cierto número de hombres competentes en reducida asociación económica, o pequeña república, en la cual cada uno conserve su propiedad y pueda, sin acudir a la fuerza, ser empleado en la categoría de trabajo para la cual tenga más capacidad», es en resumen conocido como «Ensayo para la felicidad de los pobres», o «De las repúblicas cooperativas».

Establecidos los cuáqueros en las colonias de Norteamérica (y también extendidas sus «Asociaciones de Amigos» en los Países Bajos y territorios de la Alemania actual), el propio Plockboy organizó en Manhattan en 1664 una colonia agroindustrial que fue al poco disuelta por orden del Gobernador inglés.

Pero la semilla de las comunidades de vida "al modo cuáquero» quedó bien sembrada, conectadas también con las asociaciones de socorros mutuos procedentes del mundo rural (que emigrados después a las ciudades formaron el proletariado industrial), constituyendo las formas de economía comunitaria que ha dado en llamarse precooperativismo.

Por todo ello Peter Cornelius Plockboy, como precursor del cooperativismo moderno ha sido considerado justamente el «Patriarca de la Cooperación», adelantándose con sus «repúblicas» a los «Pueblos de la Cooperación» de Robert Owen y a los «Falansterios» de Charles Fourier.

Por su parte John Bellers, nacido en 1654 y fallecido en 1752, publicó en 1695 una obrita denominada «Proposición para la creación de Asociaciones de Trabajo», basándose en los precedentes de Plockboy y los principios religiosos del amor al prójimo y en los humanistas de la solidaridad. Su sistema era igualmente colonial, de grupos de trabajo asociado que cooperativizaban el beneficio laboral percibiendo unos bonos de consumo, sustitutivos internos del dinero.

Las colonias o comunas ideadas por Plockboy y Bellers eran asociaciones cerradas de autodefensa y ayuda mutua más o menos integral (mayor integración personalista en el sistema de Plockboy), organiza- 
ciones de defensa de los trabajadores humildes frente a un sistema social abiertamente hostil.

Estas colonias tenían como limitaciones operativas de mayor entidad la falta de un espíritu empresarial como organizaciones productivas y la exigencia de un grado de aportación personal que podía llegar a ser asfixiante.

También el estar encerradas en sí mismas para evitar su destrucción por un mundo adverso, suponían el establecimiento de ghettos sin influencia sobre el conjunto de la vida social. Ello favorecería la destructiva crítica de los socialistas "científicos» contra el sistema de los asociacionistas, bajo la consideración de que los cambios sociales deberían venir por la drástica sustitución de las instituciones económicas. Y tal cambio, dado el absoluto imperio de las clases altas en la sociedad de la época, resultaría imposible sin la lucha popular.

El doble miramiento del proceso socializador se concretará, ya en el siglo XIX, por una parte en el sistema de su implantación evolutiva y pacífica (siguiendo la línea marcada por el asociacionismo cooperativista) y en el opuesto del socialismo revolucionario (con claros antecedentes en Saint-Simón y sus discípulos), postulado «científico» desde Marx (y Engels) que se autoconsideraba tal en su enfrentamiento con su contemporáneo Proudhon, asociacionista libertario, continuador del mutualismo de los siglos XVII y XVIII.

\section{Los estatalistas}

En el siglo XVIII se habían fijado como categoría sociológica la filosofía precapitalista liberal (tomada por los comerciantes como esencia de sus libertades económicas), que compuso el ideario de la lucha contra el absolutismo y los privilegios aristocráticos, pero que al propio tiempo propició el advenimiento de un mercantilismo lucrativista sin las anteriores limitaciones procedentes de la ética religiosa.

Ello supuso un nuevo escalón en la explotación de los trabajadores y, como reacción, el auge de los idearios de redención proletaria, como magistralmente estudió Otto von Gierke en su «Das Deutsche Genossenschaftrecht» (publicado en Berlín a partir de 1868, el primero de los tres volúmenes de la obra).

El siglo XVIII verá la predicación de variadas doctrinas revolucionarias y colectivistas por parte de los llamados «comunistas adelantados», como el francés Francisco Emilio Babeuf (1760-1797), "Graco», conspirador condenado a muerte por incitar al asalto popular al poder, al efecto de liquidar las clases sociales y abolir la propiedad privada, para 
llegar a un paraíso social que no concretó (una especie de comunismo anarquista).

Por su parte desde las posiciones de los asociacionistas se continuó el apostolado a favor de un humanismo solidario, caso, por ejemplo, del historiador y economista suizo Leonardo de Sismonde (1773-1842), el cual propugnó un sistema socialista, liberal y cristiano.

Pero las proposiciones más específicas fueron planteadas por el filósofo y economista francés Claudio Enrique de Saint-Simón, duque de Saint-Simón, creador de una notable escuela económica (a la que pertenecieron hombres tan ilustres como Enfantin y Bazard).

Saint-Simón, nacido en 1760 y fallecido en 1828, planteará un socialismo de Estado dirigido por macroestructuras productivas públicas, colectivizando la propiedad de los medios de producción.

Sus ideas fueron compendiadas, ya en 1830, en un volumen publicado por sus discípulos bajo el título "La Doctrina Saintsimoniana», que tuvo gran repercusión en los medios intelectuales de la época y que consagra un ideario comunista.

Estas doctrinas se basaron en la oposición frente a las rentas sin trabajo obtenidas de la plusvalía de la explotación económica, así como defendieron también el establecimiento de un mercado ordenado bajo programación gubernamental.

Se propone una sustitución económica por las rentas de trabajo («a cada uno según su capacidad, a cada capacidad según sus obras»), el trabajo asociado y la propiedad colectiva de los medios de producción bajo el control del Estado.

Las doctrinas de Saint-Simón fueron parcialmente aplicadas al cooperativismo por su discípulo Buchez, que en 1830 rompió con los saintsimonianos a causa de sus ideales religiosos, fijando en 1831 las bases de las sociedades cooperativas de trabajo asociado sobre principios cooperativos estrictos (owenistas y fourieristas).

Buchez aplicó las tesis del trabajo asociado sobre la base de la libre empresa, adscribiéndose así al cooperativismo (según el Prof. Hans Müller, «Von der Liberalen zur sozialen Genossenschaftstheorie», ese era precisamente el punto ideológico de partida de muchos cooperativistas a principios del XIX).

Los saintsimonianos, a diferencia de los asociacionistas cooperativos, no están por el escrupuloso respeto a la propiedad privada y a la herencia, ni por las aportaciones mixtas de capital y trabajo en la empresa, ni por la constitución de «asociaciones económicas libres». Por el contrario esta mentalidad cooperativa les parecía propia de ilusos.

Las generales ideas de socialización, cooperativismo, mutualidad, auxilio popular y piedad religiosa se entremezclaban, por lo que los 
pragmáticos y posibilistas las consideraban meras manifestaciones voluntaristas.

Ciertamente las ideas de los primeros asociacionistas, mutualistas y solidaristas, tienen poco de empresariales y pretendieron ser solamente un remedio a la miseria. No hay una autonomía patrimonial que permita planificar, perseguir unos claros fines productivos al efecto de llegar a competir con las sociedades mercantiles clásicas (fundamentalmente con las sociedades por acciones, entonces en pleno auge), para al menos poder pensar en una evolución económica a largo plazo de participación de los «alienados» del sistema capitalista (como les llama A. Tourain, en su obra «La Sociedad Post-industrial»).

Considerando todo ello operativamente, ordenando y dando vigor científico a las previas ideas revolucionarias, proponen los saintsimonianos un socialismo estatalista que implica una toma de previa del poder político, subvertiendo el orden tradicional al atentar contra sus pilares de la propiedad privada, la herencia, la religión y la libre empresa.

En resumen la doctrina santsimoniana proponía un dirigismo estatalista de la producción, cuyos medios estarían colectivizados (bajo titularidad pública), autogestionados por los trabajadores (convertidos en servidores del Estado y de su aparato), concibiendo en última resultancia a la comunidad toda como una «vasta asociación de productores» (así denomina la ideal sociedad santsimoniana Paul Lambert en su «Doctrina Cooperativa»).

A pesar de que este modelo de socialismo estatal hace inmediatamente pensar en un omnipotente Estado rector, los santsimonianos argumentan (adelantando también ideas marxistas) que ese Estado no será siempre todopoderoso, sino que se irá implantando una «administración de las cosas» (una economía planificada) y un «gobierno de los hombres» (una política popular).

Claro que esto no suponía una futura desaparición del Estado, como algunos han malentendido, sino simplemente el anuncio o «revelación» de un segundo tiempo en el cual las tecnoestructuras dirigentes podrían relajarse y reducir sus controles por la educación de las masas en el socialismo, auspiciándose así una liberalización de comportamientos, lo cual sólo se produce ante la seguridad y autoconfianza de un sistema.

Pero los santsimonianos no teorizaron sobre la evolución de su socialismo estatalista, por lo que parece debe entenderse que ese aperturismo sólo se produciría ante una universalización y poder tal del socialismo que convirtiera en reliquia histórica el liberalismo mercantilista. 


\section{Los pioneros del cooperativismo}

En la primera mitad del siglo XIX el ideario humanista religioso, así como el de los asociacionistas y cooperativistas, se van consolidando en un sistema alternativo de principios reglados, con métodos y fines precisos. En resumen, se va a producir la tecnificación del cooperativismo.

Cuatro autores nacidos en los últimos años del siglo XVIII van a recoger la tradición asociacionista y precooperativa, asentando en los primeros años del siglo XIX los caracteres del sistema empresarial cooperativo: Owen (nacido en 1771), Fourier (1772), King (1786) y Buchez (1796). Los tres primeros determinan los principios generales del sistema, ordenados después en los estatutos sociales de la cooperativa de Rochdale (1844), considerados como la base jurídica original del Derecho Societario Cooperativo, mientras que Buchez, que como queda dicho es una derivación saintsimoniana hacia el cooperativismo, reglamentará por vez primera los caracteres de las específicas cooperativas de trabajo asociado, "obreras» o «de producción».

A estos autores deben añadirse también, entre los doctrinarios del sistema de la primera mitad del siglo XIX, a Thompson (1785) y Derrión (1802), el primero como destacado autor de obras de ciencia económica y el segundo como práctico de la defensa consumerista (siguiendo en ello a King).

También la literatura de la época influye socialmente en favor de un sistema de economía participativa y solidaria, como es el caso de Etienne Cabet (1788), autor de la novela «El viaje a Icaria», basada en las antiguas ideas de las colonias autosuficientes, así como Pierre Leroux (1798), que en 1840 publicó su conocida obra "La Humanidad», mezcolanza de las ideas de Saint-Simón, Rousseau y Fourier, en donde se pronuncia también por un sistema social basado en el humanismo y el trabajo asociado.

Robert Owen (1771-1858), galés de Newton, era un hombre pragmático influido por las ideas solidaristas de John Bellers. En su deseo de humanizar el trabajo redujo notablemente la jornada laboral de la fábrica de Lanark de la que era directivo, aumentando al mismo tiempo los salarios. Y a pesar de las críticas de los demás empresarios consiguió con estas medidas mejorar notablemente los resultados económicos.

El éxito de sus experimentos a favor de los trabajadores le permitió dar un nuevo paso progresista, lanzándose a la defensa del «trabajo asociado». Basado en las teorías y experiencias anteriores fundó varias asociaciones integrales de producción y consumo, en forma de cooperativas mixtas, labor continuada por su discípulo E.T. Craig. 
Las indicadas asociaciones se fundaron en la idea de la propiedad privada colectiva y en la explotación comunitaria, todo ello regido por el principio de solidaridad, lo que en un mundo de feroz mercantilismo le valió a Owen el sobrenombre de «filántropo loco». Superando las críticas de sus contemporáneos llegó incluso a promover personalmente en Norteamérica toda una ciudad cooperativa («New Harmony»), aunque sin éxito.

En 1835 constituyó en Londres una Asociación Universal («para todas las clases de todas las naciones») al objeto de conseguir el cambio de mentalidad de la sociedad en favor de un sistema económico cooperativo, sobre bases racionalistas y pacifistas (ideal final de la sociedad cooperativa). En la misma intención se mostró partidario de la unificación de esfuerzos entre cooperativas y sindicatos.

Consideró el trabajo como la base del valor económico, sosteniendo que el justo precio era el valor-producción. La interrelación trabajo-consumo, con evitación al máximo de intermediarios comerciales, entendió era la mejor fórmula de paulatina consecución de una economía popular. En ese ideal fomentó unas bolsas de contratación directa entre asociaciones cooperativas y trabajadores autónomos, que fracasaron, pero supusieron un adelanto práctico del principio cooperativo de la intersolidaridad, el cual ha servido notablemente a la supervivencia de muchas cooperativas.

Charles Fourier (1772-1837), francés de Beçanzon, de familia acomodada, vivió humildemente toda su vida como modesto empleado de comercio. Inteligente observador de la realidad, dedujo que los males sociales derivaban de las injustas estructuras económicas y de la falta de participación de los trabajadores en la producción y en sus beneficios.

Desconfiando del poder político, aliado del económico, al que veía como una mera correo de transmisión de éste, entendió que la pacífica redención de los humildes sólo vendría por la autoayuda y la unión.

Por ello el nudo gordiano de su sistema cooperativo será la idea del agrupamiento de los trabajadores en organizaciones familiares (falansterios), en las que se mantendría la propiedad individual, basadas en la productividad de un trabajo común atrayente y limpio (higienista), así como en un consumo comunitario.

Las ideas de Fourier fueron sintetizadas en la obra «Nuevo Mundo Industrial», refundición de sus dispersas publicaciones menores. Aunque era partidario del abono de beneficios al aportante de capitales para los «falansterios», no consiguió financiadores de su sistema, por lo cual los creados no tuvieron éxito ya que fueron meras uniones voluntaristas sin las necesarias partidas patrimoniales. 
Tal fue el fin de las colonias creadas por sus discípulos Channing y Brisbane en las colonias americanas entre 1841 y 1845, así como la creada por Víctor Considérant en 1845 (en Texas).

Considérant (1808-1893) fue el principal discípulo de Fourier, difundiendo sus ideas por medio de la trilogía «El Destino social», publicada de 1834 a 1844. Su sistema es prioritariamente consumerista, aunque siguiendo a su maestro atienda también al trabajo asociado, por lo que desde él la defensa consumerista por medio del cooperativismo se viene denominando "fourierismo».

Sin embargo es de justicia destacar que la diferenciación participativa del socio en relación a las cooperativas de trabajo la marcó Charles Howarth, uno de los pioneros de Rochdale, que fue quien propuso en las cooperativas de consumo la distinta distribución de excedentes según el baremo consumista de los socios (principio de sencilla aplicación por el que fue conocido como «el Arquímedes de la Cooperación»).

Siguiendo su idea el también rochdaliano Abraham Greenwood fundó, en 1864, el almacén de consumo «Wholesale», en Manchester.

Los «falansterios» de Fourier tuvieron continuación en los «familisterios» de André Godin (1817-1888), obrero enriquecido y ferviente fourierista, que fundó en Guisa (Francia), en 1859, una asociación de familias obreras de objetivo consumerista, transformada en sociedad cooperativa de consumo en 1880, que perduró con gran éxito. Con ella la unión cooperativa para los abastos, suficientemente dotada de medios, se acreditó como forma práctica para la consecución y defensa del consumo popular.

Pero el primer gran doctrinario del consumerismo fue William King (1786-1865), doctor en medicina, defensor de los derechos de los consumidores desde la redacción de la revista mensual «El Cooperador», que prácticamente en solitario comenzó a publicar en 1829.

Era seguidor de las doctrinas de Owen, particularmente de la «teoría de la plusvalía». Conforme a ella sostuvo que los trabajadores no eran partícipes del auténtico beneficio de su labor, que era recibido por el capital, que en vez de obtener un interés fijo (costo productivo) dejaba ello al trabajo (costes salariales) para lucrarse con toda la plusvalía neta de la productividad, sin más justificación para ello que el propio imperio.

Por contra en las empresas cooperativas el trabajador consumerista se va haciendo con el capital, «fruto del trabajo». Para conseguir el fomento del cooperativismo pensó que se podría partir del más sencillo campo del consumo para pasar después a la producción, con financiación ya propia y con previas estructuras para dar salida a la producción. 
Personalmente constituyó en Brighton, en 1827, una cooperativa de consumo con la que tuvo un fracaso, ya que no contaba con los medios suficientes.

Como la mayor parte de los cooperativistas sostenía King que los trabajadores no debían tener esperanza en los poderes públicos, sino esperar tan sólo en su autoayuda. Por ello era acérrimo defensor de la formación y promoción educacional en el cooperativismo, preconizando la creación de instituciones para la especial enseñanza de los sistemas de organización y economía cooperativas.

Por último, debe destacarse que King es uno de los principales cooperativistas cristianos, por lo que tuvo gran predicamento entre los sectores religiosos comprometidos con el apoyo a los humildes. Dijo King, a modo de ejemplo, textualmente: "Las virtudes diarias, recomendadas por el Evangelio, constituyen el fundamento de la vida de familia y de la vida cooperativa»; y también: "Mis esperanzas consisten en tener fe en que un día los principios morales de Cristo, tal y como están incluidos en la verdadera cooperación, serán aplicados en la práctica».

Otro precursor cooperativo de importancia notable es William Thompson (1785-1833), influyente en la teoría de la economía social por su sistematización de las tesis de Bentham y Owen. Sus tres obras principales se publicaron entre 1824 y 1830, con gran repercusión entre sus contemporáneos.

En 1824 publicó la «Investigación sobre los principios de distribución de la riqueza más conducentes a la felicidad humana», obra en la que se encuadra entre los utopistas del solidarismo y la cooperación.

En 1827 publicó «Los reclamos del capital y del trabajo conciliados», obra en que se defiende el sistema del trabajo asociado con aportaciones empresariales capitalistas bajo limitaciones a su beneficio.

Y en 1830 sus «Indicaciones prácticas para el rápido y económico establecimiento de comunidades», con las que guía sobre la formación de asociaciones cooperativas, «islas de felicidad» en un mundo insolidario.

Michel Derrion (1802-1850), injustamente relegado de entre los grandes impulsores del cooperativismo, ha sido considerado por algunos como el gran práctico del consumerismo. Entendió en efecto, con notable y previsora inteligencia, que los consumidores son «la palanca motora del mundo moderno». Estaba influido por Fourier, King y SaintSimón, y sostenía que por medio del consumo popular asociado podía llegar el cambio social.

Veía el cooperativismo como un medio de unión de los trabajadores para competir y aun superar a los grandes capitalistas (ideas que reiteró Víctor A. Huber), para llegar a la larga a una sociedad solidaria. 
El mismo, junto con varios seguidores, fundó en Lyon, en 1835, una cooperativa de consumo bajo el nombre "Comercio verídico y social» en la que ofrecían productos de calidad al bajo costo que permitía la no intencionalidad lucrativa. Establecieron en ella el sistema de «puertas abiertas» y una gestión democrática compartida con los consumidores. El excedente se repartía a iguales partes (25\%) entre los trabajadores del comercio, los consumidores según su baremo de compras, el capital aportado y un fondo de obras sociales.

Fue tal el éxito de esta cooperativa que bajo presiones de los comerciantes de la ciudad fue cerrada por las autoridades en 1838, bajo la acusación de ilicitud (?) mercantil. Se había demostrado una vez más que la sociedad cooperativa, con las mínimas condiciones de viabilidad, es fórmula de notables resultados económicos y sociales.

Fhilippe Buchez (1796-1865), como ya se ha indicado, fue un destacado seguidor de Saint-Simón convertido al cooperativismo al apreciar el funcionamiento en libertad de este sistema, que no violentaba ninguna creencia o posición. Terminó siendo un convencido fourierista.

Colaboró en el periódico santsimoniano «El Productor» entre 1825 y 1830, separándose en éste último año de los muchos seguidores del movimiento por la ideología panteísta del mismo y por el totalitarismo estatalista que preconizaba, encontrando pronto acomodo en el cooperativismo en el que se apreciaban sus ideas de reorganización de la vida económica y social sobre la base de un «nuevo cristianismo», para conseguir la justicia social.

Entendió que el cambio social debiera producirse no por la estatalización económica, sino por las asociaciones coaligadas de productores (cooperativas de trabajo asociado), generando como excedente un capital. Este excedente tendría un destino económico (su reinversión mediante las reservas) y social (fondos educacionales y asistenciales), que debiera considerarse societariamente indivisible y jurídicamente indisoluble, tesis que continuadas por Louis Blanc y Raiffeisen, terminaron por ser propias del cooperativismo.

Por su confianza en la pacífica liberación de los trabajadores sin totalitarismos estatalistas fue considerado un utópico por los socialistas autoproclamados «científicos». Sin embargo, el sistema de Buchez tenía firmes bases técnicas, entre las que se incluía su propuesta de financiación mediante los llamados «Bancos del Trabajo», adelanto del crédito cooperativo.

Un resumen de su ideario, considerado como el primer asentamiento científico del cooperativismo de producción, fue publicado por Buchez en el «Diario de Ciencias Morales y Políticas» del 17 de diciembre de 1831. 
Las ideas de Buchez fueron recogidas por Louis Blanc (1812-1882), nacido en Madrid, que en 1840 publica «La Organización del Trabajo», en la que se manifiesta a favor de las asociaciones de trabajadores como fórmula para el mantenimiento del empleo, para aumentar la productividad y para conseguir la participación económica de las clases populares.

Sostuvo que el problema de la tierra se resolvería sin mayores dificultades convirtiendo en titulares de la misma a los agricultores asociados y el de la industria por medio de los «talleres sociales», especie de sociedades obreras de producción.

En principio se mostró partidario de los salarios igualitarios, pero desistió de ello por falta de operatividad, sustituyéndolos por las «distinciones salariales limitadas».

Se apartó del antiestatalismo de Buchez admitiendo al Estado como «banquero de los pobres» y como promotor de los «talleres sociales». Con el ministro de Obras Públicas, Marie, se organizaron en efecto unos «talleres sociales» (bajo el decreto del 27 de febrero de 1848) que resultaron un engaño, ya que el Gobierno abusó de su posición e impuso una disciplina y jerarquía militar en los mismos, terminando por considerar a los trabajadores meros asalariados.

A pesar de la mala experiencia con los contactos gubernamentales, Blanc terminó inclinándose hacia el estatalismo santsimoniano, sosteniendo la conveniencia de que el Estado administrara las empresas en los sectores básicos, con lo que su sistema pasó a ser un híbrido que sólo preveía la iniciativa privada en un orden menor.

Finalmente, como resumen general, puede decirse que la primera mitad del siglo XIX es la etapa histórica de normatización del cooperativismo como sistema de empresa y por ello de su especialización jurídica.

Todo va a converger en los «principios» reglamentados a partir de los estatutos de la Cooperativa de los Pioneros de Rochdale, recogidos y puestos al día por la Alianza Cooperativa Internacional (A.C.I.-I.C.A.), que desde su nacimiento en 1895, vela por el fomento y pureza del movimiento cooperativo en todo el mundo.

\section{La reglamentación cooperativa}

Las aportaciones teóricas y prácticas de los cooperativistas de la primera mitad del siglo XIX, estableciendo reglas funcionales para la operatividad empresarial de la vieja institución económica y social de la cooperación, se articulan sistemáticamente en los estatutos de la Sociedad de Rochdale, como queda dicho, cooperativa inscrita legalmente 
el 24 de agosto de 1844. En la población de Rochdale, cercana a Manchester, se fundó por 28 tejedores en paro, cesantes a consecuencia de una huelga mantenida en 1841, que estaban por ello en gran penuria económica, la "Sociedad de los Justos Pioneros», cooperativa de consumidores asentada riginalmente en un local modestísimo de la citada villa.

El local fue utilizado como depósito y central de ventas para los socios y sus familias de productos para el abasto, que adquirieron al por mayor con las aportaciones iniciales y vendieron al contado a bajo precio. Con el excedente se reaprovisionaron, proyectando el llegar con el tiempo a manufacturar productos en la medida de lo posible. Su éxito fue total, y en diez años pasaron de los 28 socios fundadores a 1.400, abriendo poco después tres sucursales.

En los estatutos originales se reglamentaron siete principios cardinales. En extracto:

1. Ayuda mutua.

2. Control societario democrático.

3. Gratuidad de cargos.

4. Libres adhesión y dimisión de los socios.

5. Compra-ventas al contado.

6. Intereses limitados al capital social.

7. Retornos cooperativos.

En 1845 se modificaron los estatutos por tres enmiendas fundamentalmente relativas a la limitación operativa de partícipes por establecimiento, al control democrático asambleario (un voto por socio «y no más») y al tipo de interés al capital, el 5\%.

En 1854 hubo una nueva modificación estatuaria de notable importancia para el desarrollo jurídico y económico cooperativista, pues se determinó en ella la política de excedentes, selevantó el mutualismo admitiendo las prestaciones a no socios, se estableció el fondo de obras sociales «para el perfeccionamiento intelectual» de los partícipes, y, por último, se estableció el carácter social de los posibles fondos remanentes en caso de extinción societaria (a «fines caritativos o públicos»).

Estos estatutos rochdalianos modificados contienen ya los seis principios básicos de la cooperación, reglas operativas jurídicas de la empresa cooperativa moderna: voluntariedad, gestión democrática, interés limitado al capital, participación en excedentes, fomento educativo-asistencial y solidaridad intercooperativa y social.

Esta reglamentación del cooperativismo lo distinguió como forma jurídica societaria, «tercera vía» entre el capitalismo y el estatalismo comunista (como se esforzó en precisar Bernard Lavergne en su libro «La 
Revolución Cooperativa o el Socialismo de Occidente», publicado en París en 1949).

La distinción entre ambas «socializaciones» se presentó con crudeza en la mitad del siglo XIX entre el libertario Proudhon (1809-1865) y el estatista Marx (1818-1883), apoyado en Engels y parcialmente en Lasalle.

Proudhon no fue originariamente cooperativista, aunque finalmente quedó "convertido» al sistema, al observar sus realizaciones prácticas. Su obra, salvo la primera «Memoria sobre la Propiedad» (1840), se publicó después de 1844. El Prof. Tulio Rosembuj publicó un esclarecedor ensayo sobre el tema («Conocer a Proudhon») en el que analiza el ideario socializador de Proudhon, antiautoritario, democrático y humanista.

Marx, de mayor preparación cultural pero no por ello de superior ingenio, trató de ridiculizarle injustamente como defensor de "utopías» por basarse en los principios de la ayuda mutua popular (entre otros escritos en su "Miseria de la Filosofía», contestación a la proudhoniana «Filosofía de la Miseria»).

Después de haberlas combatido doctrinalmente, pero convencido por su eficacia y nobles principios, defendió Proudhon apasionadamente a las cooperativas de trabajo asociado como fórmula productiva social (cambiando con gran honestidad intelectual sus anteriores juicios).

Además puede considerarse a Proudhon como uno de los «inventores» del crédito mutuo, diferenciándose del alemán ShultzeDelitzsch (el otro pionero del crédito mutual) en que no preveía un dividendo para los partícipes. Proudhon entendía que el interés al capital, más que una «legitimidad», tenía un carácter de necesidad práctica, pues era la única fórmula para que las asociaciones laborales obtuvieran patrimonio inicial con el que comenzar los objetivos productivos. Y sostenía que, en todo caso, debe imponerse el derecho al posterior "rescate» capitalizando con beneficios y reservas sociales.

Pero lo cierto es que a pesar de las lógicas discrepancias sobre el sistema cooperativo, la asunción de una reglamentación del sistema y su practicidad como fórmula empresarial, permitieron que a partir de la segunda mitad del siglo XIX comenzaran a promulgarse especiales legislaciones cooperativistas, significadamente la ley inglesa de 1852, las leyes francesa y portuguesa de 1867, la alemana de 1868, la belga de 1873 y la japonesa de 1900 .

El reconocimiento del cooperativismo en el Derecho Societario supone una acreditación de su «mayoría de edad», lo que permitirá su 
autónomo desarrollo en los últimos años del siglo XIX y su expansión en el XX.

Complementariamente, en la segunda mitad del siglo XIX se denota en el cooperativismo el inicio de una practicismo economicista de las cooperativas como empresas. Se parte para ello de la autofinanciación, instrumentada tanto en el cooperativismo de crédito industrial (Schulze y Luzzatti) como en el de crédito agrícola (Raiffeisen y Wollemborg), abandonándose también la vieja idea de las colonias agrícolas integrales sustituidas por un moderno cooperativismo agrícola (Haas).

Hermann Schulze-Delitzsch (1808-1883), juez de Delitzsch, es uno de los pioneros del cooperativismo alemán. Su popularidad le llevó a conseguir un acta de diputado de la Asamblea Nacional prusiana (1848), para la que posteriormente preparó el borrador de base del Código Cooperativo de Prusia del 27 de marzo de 1867.

Publicó diversos artículos sobre asociacionismo cooperativo, fundando al propio tiempo varias sociedades cooperativas (singularmente una Caja de Socorros Mutuos y una Sociedad de Crédito, con la idea de llegar al establecimiento de «Bancos Populares»).

Con pragmático espíritu comprendió que la empresa cooperativa debía ajustarse a cada momento histórico y a las circunstancias sociopolíticas, manteniendo su norte ético (los principios del sistema). A largo plazo previó un agigantado cooperativismo de producción, fruto de consorcios entre cooperativas que llevarían a la formación de grandes empresas y grupos cooperativos, con cabida también para los pequeños empresarios y comerciantes, absorbidos o unificados económicamente por uniones productivas y de organización.

Luigi Luzzatti (1841-1927), descendiente de una rica familia judía veneciana, político y profesor universitario, fue un destacado seguidor de Schulze, cuyo sistema conoció en su época de estudiante en Berlín.

Su obra «La Difusión del Crédito y la Banca Popular», publicada en Padua en 1863, tuvo un gran eco social y sirvió de base a los defensores del crédito cooperativo. Es famosa su máxima bancaria cooperativa: «Convertir en capital la honestidad». En 1907 participó en la apertura del Congreso Cooperativo de Cremona en el que abogó por el crédito cooperativo como fórmula financiera de una economía solidaria.

Participó en la creación de bancos cooperativos en Lodi y Milán, participando también en la propuesta de creación en Roma de un Instituto Central de Crédito entre las organizaciones cooperativas y la administración pública.

F.W. Raiffeisen (1818-1888), alcalde de Weyerbuch y de Heddesford, hijo de un pastor luterano, es considerado el «padre» de las cajas rurales (cooperativismo de crédito agrícola). Publicó en 1866 un ensayo 
en torno al asociacionismo cooperativista agrícola que tuvo notable éxito, siendo reeditado por cinco veces hasta su fallecimiento. Fundó una "Sociedad de Socorros Mutuos» y la Cooperativa de Crédito de Heddesford.

Las bases de su sistema se pueden resumir en la limitación territorial de cada cooperativa, en aras de la mayor operatividad; la exigencia de cualidades morales en los partícipes y la gratuidad de los cargos ejecutivos; la exigencia de aportaciones patrimoniales y la negación del ánimo lucrativo (todos los excedentes deben tener como destino los fondos de reserva y los educativos y asistenciales).

Como continuador de la obra de Raiffeisen debe destacarse a Leone Wollemborg (1859-1932), nacido en Padua, propagandista de los beneficios para el campo del fomento de las cajas rurales. Su librito "Le Casse Cooperativi di Prestiti», publicado en Padua en 1884, tuvo gran repercusión entre las organizaciones campesinas.

Por su parte, Wilhelm Haas (1839-1931) fue el sistematizador del cooperativismo agrícola. Su ideario operativo está recogido en el Ilamado "Programa de Darmastadt», que resume las conclusiones del Congreso Alemán de las Cooperativas Agrícolas que se celebró en dicha ciudad.

La base de la unión agrícola de Haas fue el principio económico del aprovechamiento común, abaratador y mejorador de las explotaciones, de donde se pasó a las centrales lecheras y a las cajas de crédito rural.

En 1883 fue nombrado presidente de la Unión de Cooperativas Agrícolas de Alemania, puesto desde el que ejerció gran influencia en la organización del cooperativismo agrícola sobre bases pragmáticas.

Todas estas ideas y realizaciones de los teóricos y prácticos del nuevo cooperativismo de la segunda mitad del siglo XIX, llevaron a que en el siglo Xx se acentuara la visión empresarial de las cooperativas, pasando a segundo plano el elemento "redentorista» del movimiento cooperativo. Se abandonaron las prácticas de vida comunitaria (colonias, falansterios, etc.), para centrarse en la cooperativa como forma societaria económica, al objeto de intervenir en la mercantilidad mediante una empresa participativa y democrática, esencia de la economía social.

\section{La empresa cooperativa}

Las bases asentadas en la segunda mitad del siglo XIX del nuevo cooperativismo dieron lugar, por su continuación y perfeccionamiento 
técnico en el XX, a la empresarialización de la sociedad cooperativa en el contexto mercantilista, como queda apuntado. La fórmula cooperativa pasa de los utopismos al sistema de empresa, sobre la fundamental base de la democratización económica como medio superador del capitalismo y consecutor de la justicia social.

Aunque este movimiento es multipersonal y de base popular puede destacarse el influjo original de la llamada Escuela de Nimes y del economista Charles Gide. Esta afamada escuela fue fundada por Boyve y Fabre, participando en ella autores de gran prestigito como Lavergne, Poisson, Lasserre y el citado Gide (desde 1885), entre otros.

Gide (1847-1932) pesó notablemente en la doctrina de la Escuela defendiendo los principios economicistas para el logro de un cooperativismo práctico. Su base científica, como catedrático de Economía en París, fue vital para el mantenimiento del rigor en la defensa de los postulados cooperativos frente a los de la empresa capitalista. Su obra principal, «Principios de Economía Política», fue el aval científico de los defensores de un nuevo orden económico superador de los inconvenientes sociales del capitalismo.

Pensó que un medio para la superación del capitalismo era la unión consumerista, defensora de los intereses de los consumidores por su asociacionismo y, empresarialmente, por su adscripción a las cooperativas de consumo. Con ello siguió la vieja doctrina de Michel Derrión, auspiciando también un futuro "reinado del consumidor».

La táctica con la que proveyó a las cooperativas de consumo era de largo plazo y en tres fases: primera, la de paulatina conquista del comercio bajo el principio del «justo precio», el no lucrativismo y la defensa del consumidor; segunda, la de adquisición o consorcio con explotaciones agrícolas y cooperativas agrarias; y tercera, la adquisición de manufacturados procedentes de las cooperativas de trabajo asociado.

Los fines de este cooperativismo mercantilista eran claros:

1. Evitar las luchas sociales, siempre llenas de dolorosas secuelas para los más humildes.

2. ${ }^{\circ}$ Ir pacíficamente a la paulatina abolición del capitalismo, que dificulta la consecución de la justicia social.

3. Llegar a una economía, y por consecuencia a una sociedad, democrática y solidaria.

La idea de la democracia empresarial fue también sostenida, entre otros coetáneos de Gide, destacadamente por León Walras, economista defensor de un socialismo liberal, muy influyente entre los economistas progresistas. 
Todas estas ideologías eran coincidentes con los postulados del pensamiento social y del solidarismo, sirviendo de aglutinantes en la formación de la Internacional Cooperativa (A.C.I., Londres-1985/París1896), propulsora del «nuevo orden cooperativo» en todo el orbe, bajo el escrupuloso respeto de los principios del sistema.

El cooperativismo va en su expansión siendo más y más pluralista, esenciándose el sistema en fin en la idea de democratización económica (como destacara el profesor de la Universidad de Lieja, Paul Lambert). Por ello va confluyendo el cooperativismo con todas las doctrinas deseosas de conseguir la democracia en la empresa, de manera que muchos sindicatos, partidos políticos y programas gubernativos asumen el ideal cooperativo como consustancial a la Democracia.

No es por consiguiente casualidad, que en la primera mitad del siglo xx destacados autores hayan defendido el ideario cooperativo, como el primer director de la Organización Internacional del Trabajo (O.I.T), Albert Thomas (fallecido en 1932), o su ilustre dirigente George Fauquet (1953), o los insignes profesores universitarios G.D.H. Cole (Oxford), W. Sombart (Jena), G. Mladenatz (París) o F. Milhaud (Ginebra).

\section{Tendencias cooperativas}

No es fácil la clasificación del cooperativismo por bloques ideológicos, pues al ser un movimiento populista y universal se han producido históricamente muchas y variadas tendencias en él, además de que por su carácter solidarista y humanista ha sido considerado instrumento de utilidad por numerosas creencias e ideologías.

Por todo ello han confluido en el apoyo doctrinario cooperativista pedagogos y políticos, religiosos y sindicalistas, libertarios y transformativos, humanistas $y$, en general, toda suerte de pensadores deseosos de llegar a la felicidad social. Y esa universalidad es precisamente una gran riqueza del sistema cooperativo. En efecto, toda ideología sustentadora del noble deseo de la justicia social se acerca al cooperativismo. Los principios de democracia y libre adhesión del mismo lo hacen posible. A nadie se le condiciona por ninguna motivación personalista previa y por ello todos pueden ser amparados por la solidaridad cooperativa.

Su fuerza como medio de justicia y pacificación sociales es posiblemente única para alcanzar el deseo de armonía universal, la gran utopía de la humanidad. Haya justicia social y goce después cada cual de sus libertades con toda amplitud de conciencia. 
Pero a causa de la pluralidad del cooperativismo los intentos clasificatorios del mismo suelen ser muy variados, precisamente por tratar de recoger todos los matices históricos del pensamiento cooperativista, utilicen o no directamente tal denominación.

Pero en beneficio de la concisión y con criterio globalizador, pueden unificarse las tendencias doctrinales del sistema en cuatro grandes bloques, en los que se dan, a su vez, variedad de posturas ideológicas.

La clasificación podría comenzar por los meros «movimientos sociales y la pedagogía social», continuar con los «socialistas-asociacionistas», seguir con los «cristianos sociales» y terminar por los movimientos «solidaristas».

En origen, como se ha repetido en múltiples ocasiones, el cooperativismo es un movimiento natural y popular de solidaridad y mutua ayuda. No es una creación de intelectuales sino del pueblo. Por ello sus pioneros se confunden con los precursores de la socialización. Como decía el profesor Sombart "el cooperativismo es un socialismo racionalista», puesto que la necesidad de la reforma social es una cuestión de la razón.

Estas inquietudes populares conectan con las teorías moralizadoras de los teóricos de la pedagogía social. Entre otros muchos, destacadamente, Pestalozzi (1746-1827) y Mazzini (1805-1872). El primero como defensor de la autoayuda social y de los humanos sentimientos solidarios, propugnaba un asociacionismo y un cooperativismo asistemáticos; Giuseppe Mazzini hacía referencia más directamente al cooperativismo como fórmula societaria de redención para los trabajadores. En su obra principal, «Los Derechos del Hombre», se refiere al trabajo asociado «libre, voluntario, entre personas que se aman y respetan mutuamente». Se trata de conseguir una sociedad más justa por la natural atención a la ética social.

Una mayor concreción doctrinal se produce en los llamados «socialistas asociacionistas», llamados así por Gide porque consideraban a las asociaciones laborales una fuerza suficiente para impulsar la resolución del «problema social», como primer estadio para llegar a la justicia social.

La práctica totalidad de los pioneros cooperativos (Owen, Fourier, Buchez...), pueden incluirse en esta tendencia, puesto que consideraban la cooperación como una fórmula económica contra los defectos del capitalismo.

Es por ello que los pioneros cooperativos recibieron el sobrenombre de utópicos, muy concretamente por los estatalistas santsimonianos y, más tarde, por el marxismo.

Conectando con los viejos estatalistas el llamado «socialismo real» (o no democrático), al considerar al Estado como único dirigente económico (ya Ferdinand Lasalle decía del Estado que debía ser «la aso- 
ciación en grande de las clases obreras») y principalísimo titular de la producción y sus medios, o ha mostrado poca fe en las asociaciones cooperativas o las ha utilizado en la práctica con poco respeto a los principios del sistema, con lo que se ha perdido una oportunidad de oro para conseguir una socialización democrática.

Una ideología cooperativista de gran influencia la componen los llamados "cristianos sociales», que no pueden ser unificados en una escuela, sino que desde distintos planos ideológicos confluyen en el deseo último de la consecución de una solidaridad, basada en el amor cristiano al prójimo. Por ello cristianos de todas las épocas han rechazado el dogma económico del liberalismo individualista y han optado por la defensa del cooperativismo como medio práctico para alcanzar sus altos ideales.

Ya Buchez, en 1938, en su "Ensayo de un tratado completo de Filosofía desde el punto de vista del Catolicismo y del Progreso», analizó con criterios técnicos la aplicabilidad del cristianismo a las asociaciones cooperativas (antes otros cooperativistas habían incidido en el deseo de conseguir la justicia social por la aplicación de los principios del cristianismo, como Bellers y King, entre otros muchos).

François Huet, en 1853, se refirió también a ese socialismo cristiano en su obra «El Reino Social del Cristianismo», en el que sueña con una sociedad humanista por la aplicación del cristianismo a la producción y a las relaciones sociales en general.

El mismo Gide, en un artículo de divulgación económica titulado «Christianisme Social», estudió las ventajas del cooperativismo para los cristianos, como sistema económico que no lesiona la ética del amor al prójimo y permite llegar a una solidaridad práctica y realista (un caso notable de realismo cooperativista cristiano y humanista es el del sacerdote Don José María Arizmendiarreta, pionero del Ilamado «Grupo Cooperativo de Mondragón», cuyo auténtico milagro fue iniciar el pensamiento por el que fue posible establecer un gran grupo cooperativo partiendo prácticamente de la nada).

\section{Bibliografía}

D. Benevides Pinho, «Evolución del Pensamiento Cooperativista». Intercoop, Buenos Aires, 1987.

A. Kaplan y B. Drimer, «Las Cooperativas: Fundamentos, Historia y Doctrina». Intercoop, Buenos Aires, 1981 (3. ${ }^{\text {a edic.). }}$

J. Divar Garteiz-AurReCOA, «Las Cooperativas: una alternativa económica». Dykinson, Madrid, 2011. 